supplementation, especially to extremely premature infants or those with documented hypothyroxinemia remains a research priority.

Competing interests: None; Funding: Nil.

\section{REFERENCES}

1. Simic N, Asztalos EV, Rovet J. Impact of neonatal thyroid hormone insufficiency and medical morbidity on infant neurodevelopment and attention following preterm birth. Thyroid. 2009; 19:395-401.

2. Reuss ML, Paneth N, Pinto-Martin JA, Lorenz JM, Susser $\mathrm{M}$. The relation of transient hypothyroxinemia in preterm infants to neurologic development at two years of age. New Eng J Med. 1996;334:821-7.

3. Den Ouden AL, Kok JH, Verkerk PH, Brand R, VerlooveVanhorick SP. The relation between neonatal thyroxine levels and neurodevelopmental outcome at age 5 and 9 years in a national cohort of very preterm and/or very low birth weight infants. Pediatr Res. 1996;39:142-5.

4. Meijer WJ, Verloove-Vanhorick SP, Brand R, van den Brande JL. Transient hypothyroxinaemia associated with developmental delay in very preterm infants. Arch Dis Child. 1992;67:944-7.

5. Delahunty C, Falconer S, Hume R, Jackson L, Midgley P, Mirfield M, et al. Scottish Preterm Thyroid Group. Levels of neonatal thyroid hormone in preterm infants and neurodevelopmental outcome at $51 / 2$ years: millennium cohort study. J Clin Endocrinol Metab. 2010;95:4898-908.

6. Dilli D, Eras Z, Andiran N, Dilmen U, Sakrucu ED. Neurodevelopmental evaluation of very low birth weight infants with transient hypothyroxinemia at corrected age of 18-24 months. Indian Pediatr. 2012;49:711-5.

7. Brook CGD. Do preterm infants need thyroxine replacement? BMJ. 1996;312:1133-4.

8. Karna P. Developmental follow-up of very low birthweight premature infants with low free thyroxine. Am J Perinatol. $1991 ; 8: 288-91$.

\title{
Late Preterm Births: Major Cause of Prematurity and Adverse Outcomes of Neonatal Hyperbilirubinemia
}

\author{
VINOD K BHUTANI \\ Stanford University School of Medicine and Lucile Packard Children's Hospital, \\ Department of Pediatrics, Division of Neonatal and Developmental Medicine, 750 Welch Ave \#315; Stanford, CA 94304. \\ bhutani@stanford.edu
}

$\mathrm{O}$ ccurrence and consequence of late preterm births (239 to 259 days of gestational age, GA) is a public health problem that is preventable. These infants account for the bulk of a nation's preterm population (of all USA preterm births, $74 \%$ are late-preterm), adversely impact on national breastfeeding rates, increase direct healthcare cost by need for readmission of infants for severe hyperbilirubinemia and hypernatremic dehydration, as well as increase the risk for irreversible brain damage due to kernicterus [1-4].

As a sub-cohort of the preterm population, latepreterm infants masquerade as term infants $(<37$ weeks and $0 / 7$ days of GA) on the basis of their relatively mature appearance, but remain physiologically and metabolically immature [2]. Currently, most late preterm infants are cared for by their mothers and discharged home with unmonitored home care. Consequently, late-preterm infants are at higher risk than term infants of developing medical complications that result in higher rates of mortality and morbidity, and have higher rates of hospital readmission during the neonatal period than term infants.
Maturational factors that impact postnatal adaptation include brain and autonomic nervous system growth and induction of hepatic metabolic pathways. The brain volume of an infant at 36 weeks GA is only about $60 \%$ of that for a term infant [5]. Reduced number of sulci and gyri reflect an anatomic in maturity that is defined by the white matter, myelination and cortical migration of neuronal cells. Late-preterm infants are also more susceptible to gray matter injury induced by hypoxiaischemia than the term infant. Low oromotor tone, function, and neural maturation also predispose these infants to dehydration and hyperbilirubinemia that are associated with poor feeding in the breastfed infant. Breastfeeding of a preterm infant also requires special coaching of the mother [7]. Decreased maternal breast stimulation and decreased breast emptying and lead to suboptimal milk transfer to the baby as well as decreased maternal milk production. This leads to excessive weight loss and decreased bilirubin excretion leading to dehydration, slow postnatal weight gain and newborn jaundice. Jaundice and hyperbilirubinemia occur more commonly and are more prolonged among late preterm infants than term infants because of delayed maturation 
and a lower concentration of uridine diphosphoglucuronate glucuronosyltransferase and immature gastrointestinal function. Feeding difficulties that predispose them to an increase in enterohepatic circulation of bilirubin, decreased stool frequency, dehydration, and hypernatremia add to the overall bilirubin load and risk of toxicity.

In a recent commentary, relying on independent reviews of available evidence, Maisels, et al. [3] recommend a more structured approach to management and follow-up according to the predischarge bilirubin, GA, and other clinical risk factors for hyperbilirubinemia in order to prevent adverse outcomes due to severe neonatal hyperbilirubinemia. Experience and reports indicate that each week of GA immaturity is associated with higher incidence of severe hyperbilirubinemia such that the morbidity rate, due to hyperbilirubinemia doubles for each week $<39$ weeks of GA. Current review supports a pre-discharge bilirubin expressed as a risk zone on an hour-specific bilirubin nomogram as a simple and accurate means for determining the risk of developing significant hyperbilirubinemia and the most accurate risk-assessment strategy incorporates information about bilirubin values, clinical risk factors and GA [1,3]. The study reported by Lavanya, et al. [7] validates the predictive role of bilirubin between 24 to 48 hours age for a select population of late preterm infants from a single urban birthing facility. However, it is important not to underestimate the clinical relevance of the contributory roles of other factors such as race/ ethnicity, degree of immaturity, bruising, blood group incompatibility, G6PD deficiency, breastfeeding success and infant vulnerabilities to inherent, familial or genetic co-morbidities. Adverse outcomes among late preterm infants are thus dependent on patient population mix and clinical practice patterns.

Competing interests: None stated; Funding: Nil

\section{REFERENCES}

1. American Academy of Pediatrics, Subcommittee on Hyperbilirubinemia. Management of Hyperbilirubinemia in the Newborn Infant 35 or More Weeks Of Gestation. Pediatrics. 2004;114:297-316.

2. Engle WA, Tomashek KM, Wallman C: Committee on Fetus and Newborn, American Academy of Pediatrics. "Late-preterm" infants: A population at risk. Pediatrics. 2007;120:1390-1401.

3. Maisels MJ, Bhutani VK, Bogen D, Newman TB, Stark AR, Watchko JF. Hyperbilirubinemia in the newborn infant $>$ or $=35$ weeks' gestation: an update with clarifications. Pediatrics. 2009;124:1193-8.

4. Bhutani VK, Vilms RJ, Hamerman-Johnson L. Universal bilirubin screening for severe neonatal hyperbilirubinemia. J Perinatol. 2010;30(Suppl): S6-15.

5. Kinney H C. The near-term (late preterm) human brain and risk for periventricular leukomalacia: a review. Sem Perinatol. 2006;30:81-8.

6. Walker M. Breastfeeding the late preterm infant. J Obstet Gynecol Neonatal Nurs. 2008;37:692-701.

7. Lavanya KR, Jaiswal A, Reddy P, Murki S. Predictors of significant jaundice in late preterm infants. Indian Pediatr. 2012;49:717-20. 